\title{
Direct Capture of Organic Acids from Fermentation Media Using lonic Liquids
}

November 2004

Prepared by

K. Thomas Klasson

Whitney B. Ridenour

Brian H. Davison

Joanna McFarlane 


\title{
DOCUMENT AVAILABILITY
}

Reports produced after January 1, 1996, are generally available free via the U.S. Department of Energy (DOE) Information Bridge:

Web site: http://www.osti.gov/bridge

Reports produced before January 1, 1996, may be purchased by members of the public from the following source:

\author{
National Technical Information Service \\ 5285 Port Royal Road \\ Springfield, VA 22161 \\ Telephone: 703-605-6000 (1-800-553-6847) \\ TDD: 703-487-4639 \\ Fax: 703-605-6900 \\ E-mail: info@ntis.fedworld.gov \\ Web site: http://www.ntis.gov/support/ordernowabout.htm
}

Reports are available to DOE employees, DOE contractors, Energy Technology Data Exchange (ETDE) representatives, and International Nuclear Information System (INIS) representatives from the following source:

Office of Scientific and Technical Information

P.O. Box 62

Oak Ridge, TN 37831

Telephone: 865-576-8401

Fax: 865-576-5728

E-mail: reports@adonis.osti.gov

Web site: http://www.osti.gov/contact.html

\begin{abstract}
This report was prepared as an account of work sponsored by an agency of the United States Government. Neither the United States government nor any agency thereof, nor any of their employees, makes any warranty, express or implied, or assumes any legal liability or responsibility for the accuracy, completeness, or usefulness of any information, apparatus, product, or process disclosed, or represents that its use would not infringe privately owned rights. Reference herein to any specific commercial product, process, or service by trade name, trademark, manufacturer, or otherwise, does not necessarily constitute or imply its endorsement, recommendation, or favoring by the United States Government or any agency thereof. The views and opinions of authors expressed herein do not necessarily state or reflect those of the United States Government or any agency thereof.
\end{abstract}


ORNL/TM-2004/192

Nuclear Science and Technology Division

\title{
DIRECT CAPTURE OF ORGANIC ACIDS FROM FERMENTATION MEDIA USING IONIC LIQUIDS
}

\author{
K. Thomas Klasson* \\ Whitney B. Ridenour $\dagger$ \\ Brian H. Davison $\ddagger$ \\ Joanna McFarlane
}

Date Published: November 2004

\author{
Prepared by \\ OAK RIDGE NATIONAL LABORATORY \\ P.O. Box 2008 \\ Oak Ridge, Tennessee 37831-6283 \\ managed by \\ UT-Battelle, LLC \\ for the \\ U.S. DEPARTMENT OF ENERGY \\ under contract DE-AC05-00OR22725
}

*U.S. Department of Agriculture, New Orleans, La.

$\dagger$ The University of Tennessee, Knoxville (student)

†Life Sciences Division, ORNL 



\section{CONTENTS}

\section{Page}

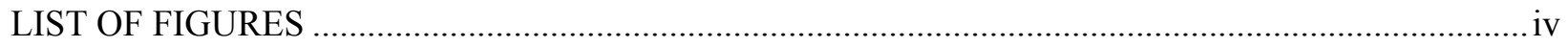

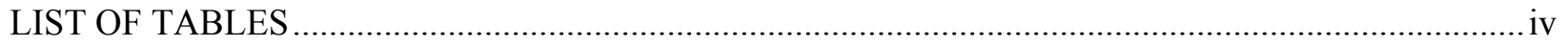

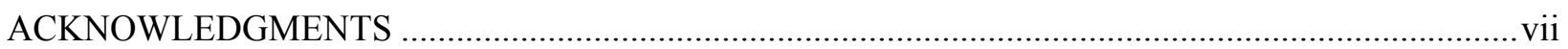

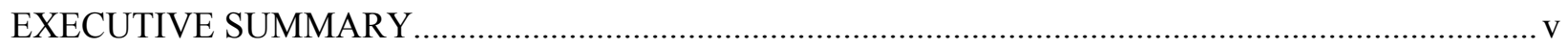

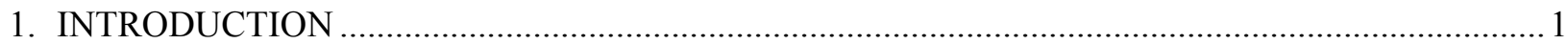

2. MATERIALS AND METHODS

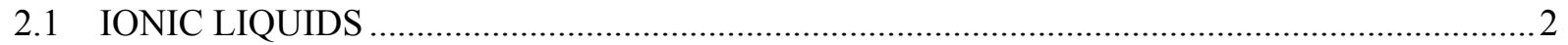

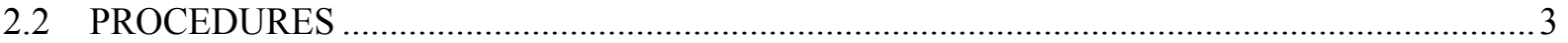

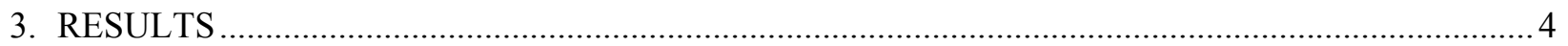

3.1 EXTRACTION OF SUCCINIC ACID FROM FERMENTATION MEDIUM …......................... 8

3.2 ESTIMATION OF CONTINUOUS LIQUID-LIQUID EXTRACTION REQUIREMENTS ....... 9

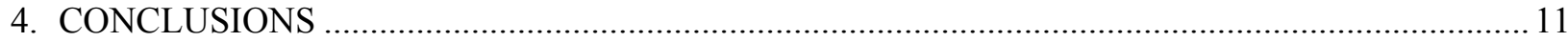

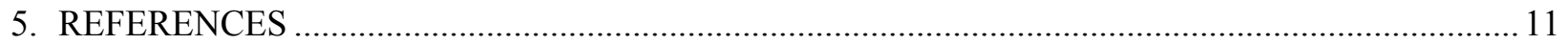




\section{LIST OF FIGURES}

Figure

Page

1 Trihexyltetradecylphosphonium methanesulfonate. .............................................................. 2

2 Trihexyltetradecylphosphonium dodecylbenzenesulfonates....................................................... 3

3 Tributyltetradecylphosphonium dodecylbenzenesulfonates. ...................................................... 3

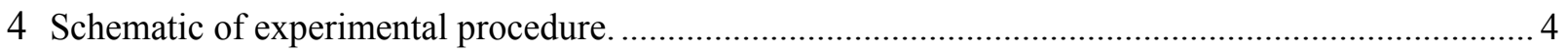

5 Results from scoping studies with ionic liquids from Merck....................................................... 5

6 Scoping studies with ionic liquid containing sulfonate(s) anions.............................................. 6

7 Succinic acid distribution coefficient as a function of $\mathrm{pH}$ at room temperature for different

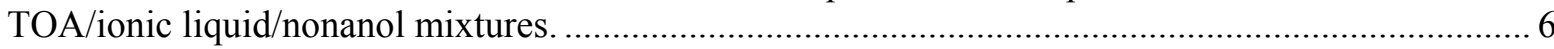

8 Succinic acid distribution coefficient for different temperatures with TOA/trihexyltetradecylphosphonium methanesulfonate/nonanol. ................................................... 7

9 Results from comparison study with extraction solvent suggested by Hong.................................. 8

10 Distribution coefficient as a function of succinic acid concentration. ............................................ 9

11 Equilibrium diagram and working graph for determining theoretical extraction stages.................. 10

12 Schematic of extraction stages for succinic acid extraction from aqueous to ionic liquids............... 10

\section{LIST OF TABLES}

Table

Page

1 Fermentation medium for production of succinic acid. 


\section{ACKNOWLEDGMENTS}

This work was supported by the Oak Ridge National Laboratory's State Partnership Program and administered by the U.S. Department of Energy's Energy Efficiency and Renewable Energy Program.

Several of the ionic liquids used in this study were kindly supplied by Dr. Rex Ren of Wesleyan University (Middleton, CT) and Dr. Huimin Luo in the Nuclear Science and Technology Division at Oak Ridge National Laboratory. 


\section{EXECUTIVE SUMMARY}

Several ionic liquids have been investigated for the extraction of organic acids from fermentation broth. Partitioning of representative organic acids (lactic, acetic, and succinic) between aqueous solution and nine hydrophobic ionic liquids was measured. The extraction efficiencies were strongly dependent on $\mathrm{pH}$ of the aqueous phase. Distribution coefficient was very good (approximately 60) at low succinic acid concentrations for one of the ionic liquids (trihexyltetradecylphosphonium methanesulfonate) at neutral $\mathrm{pH}$. However, this ionic liquid had to be diluted with nonanol due to its high viscosity in order to be useful. A diluent (trioctylamine) was also added to this mixture. The results suggest that an extraction system based on ionic liquids may be feasible for succinic acid recovery from fermentation broth and that two ideal extraction stages are needed to reduce the concentration from $33 \mathrm{~g} / \mathrm{L}$ to $1 \mathrm{~g} / \mathrm{L}$ of succinic acid. Further studies are needed to evaluate other issues related to practical applications, including ionic liquid loss in the process, toxicity effects of ionic liquids during simultaneous fermentation and extractions. 


\section{INTRODUCTION}

Ionic liquids are a new class of solvents that may promise reduced energy usage and minimized emissions in replacing conventional solvents in industrial chemical processes (1). Typically, these liquids are composed of combinations of two large ions, with at least one of them organic in nature. Ionic liquids offer several potential advantages, including new chemistries with improved kinetics, selectivities, and yields (2). They support greater, longer-lasting catalytic activity at milder processing conditions (lower temperatures and pressures). Their extremely low vapor pressure could be employed in improved processes for greatly reduced solvent loss, less air pollution, and easier separations that could result in large energy savings compared to traditional separations processes. Despite the attractive promise of new "green" processes based on ionic liquids, development of industrial technologies utilizing the unique properties of these fluids as solvents or in separations processes has been hampered by a lack of process data upon which industry can evaluate technical and economic feasibility.

Liquid-liquid extraction is a mature technology and extraction of chemicals produced via fermentation has been the topic of many research activities and patents. Baniel et al. described extraction and back extraction of carboxylic acids such as lactic or citric acid in an amine-based solvent system $(3,4,5,6,7)$. Replacement of filtration and crystallization in fermentation-based succinic acid production with low-cost liquid-liquid extraction was suggested as a method for improving process economics (8). Several aspects of extractive fermentation as well as general approaches to two-phase bioreactor systems have been discussed in a recent review paper (9). Computer-aided design of solvents in extractive fermentation have been proposed by Wang and Achenie, addressing issues such as biocompatibility, easy of separation, stability, and inertness to reactions (10). Often, solvents are not used in the pure form-Hong et al. found that when tri-alkylamines were added to octanol the extraction of succinc acid from water was improved (11).

Extractive fermentation or extraction of fermentation products with ionic liquids has been suggested and recently reported in the literature. Ionic liquids, such as 1-butyl-3-methylimidazolium hexafluorophosphate, have been used to extract fermentation chemicals (e.g., erythromycin) and have shown good biocompatibility in fermentation experiments with Rhodococcus R312 (12). Amino acids produced via fermentation have also been recovered by the same ionic liquid containing a small amount of crown ether (13). However, investigators tested 1-butyl- and 1-octylmethylimidazolium hexafluorophosphate for extraction of butanol from fermentation medium and expressed concerns about toxicity (14). Results obtained by Matsumoto et al. from lactic acid fermentation experiments suggest that imidazolium-based ionic liquids containing tributyl phosphate were not toxic to Lactobacillus rhamnosus and performed the same as conventional organic solvents (15).

The focus of this study was on the collection of preliminary data for extraction of organic acids from fermentation broth. The recovery of fermentation products such as succinic and lactic acids is often costly and technically challenging. The U.S. Department of Energy Vision 2020 Advanced Separations Team has evaluated the potential impact of biobased products and identified the "direct capture of products from biotransformations" as the most significant barrier to large-scale implementation (16). 


\section{MATERIALS AND METHODS}

Liquid extraction experiments were carried out with different ionic liquids and ionic liquid mixtures to determine if they could be used for the recovery of fermentation products. Several aqueous stock solutions were prepared at different organic acid concentrations with either brine or deionized water with a mixture of lactic, acetic, hexanoic, and succinic acids. Single-component solutions of succinic acid in water were also prepared. The solutions were prepared in volumetric flasks by adding organic acids at several concentrations and adjusting to a desired $\mathrm{pH}$. The stock solution, containing $1-100 \mathrm{~g} / \mathrm{L}$ of organic acid, was then contacted with several different ionic liquid solvents. After contact, the aqueous phases were analyzed by high-performance liquid chromatography (HPLC) for organic acids.

\subsection{IONIC LIQUIDS}

Twelve ionic liquids and ionic-liquid/solvent mixtures were tested for their extraction potential of organic acids from aqueous phases:

1. butylmethylimidazolium bis(trifluoromethanesulfonyl)imide

2. octylmethylimidazolium bis(trifluoromethanesulfonyl)imide

3. butylmethylimidazolium hexafluorophosphate

4. trihexyl(tetradecyl)phosphonium bis(trifluoromethanesulfonyl)imide

5. 1-hexyl-3-methyl-imidazolium bis(trifluoromethanesulfonyl)imide

6. 1-butyl-1-methyl-pyrrolidinium bis(trifluoromethanesulfonyl)imide

7. trihexyltetradecylphosphonium methanesulfonate (Fig. 1)

8. trihexyltetradecylphosphonium dodecylbenzenesulfonates (

9. tributyltetradecylphosphonium dodecylbenzenesulfonates (

Fig. 3)

Ionic liquids 1 through 3 were produced and obtained from Dr. Huimin Luo in the Nuclear Science and Technology Division at Oak Ridge National Laboratory. These ionic liquids were chosen because of their low viscosities, their hydrophobicity, and their success with other organic extractions from aqueous phases such as toluene and complex organic acids (17). Some of these ionic liquids were also tested with the diluent nonanol. Ionic liquids 4 through 6 were obtained from Merck KGaA (Darmstatd, Germany) and were selected due to their hydrophobic properties and because they were either soluble or miscible with several organics. Ionic liquids 7 through 9 were kindly supplied by Dr. Rex Ren of Wesleyan University (Middleton, CT). These ionic liquids were chosen based on their extreme hydrophobicity. The ionic liquids obtained from Dr. Ren were very viscous and were diluted with nonanol to a 50 vol \% mixture with stirring for 2 hours.

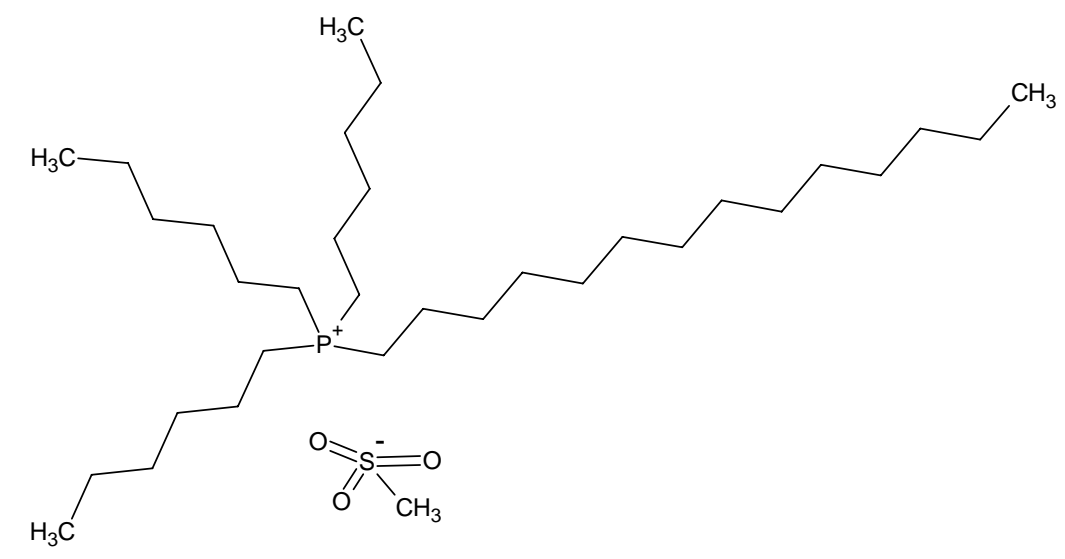

Fig. 1. Trihexyltetradecylphosphonium methanesulfonate. 


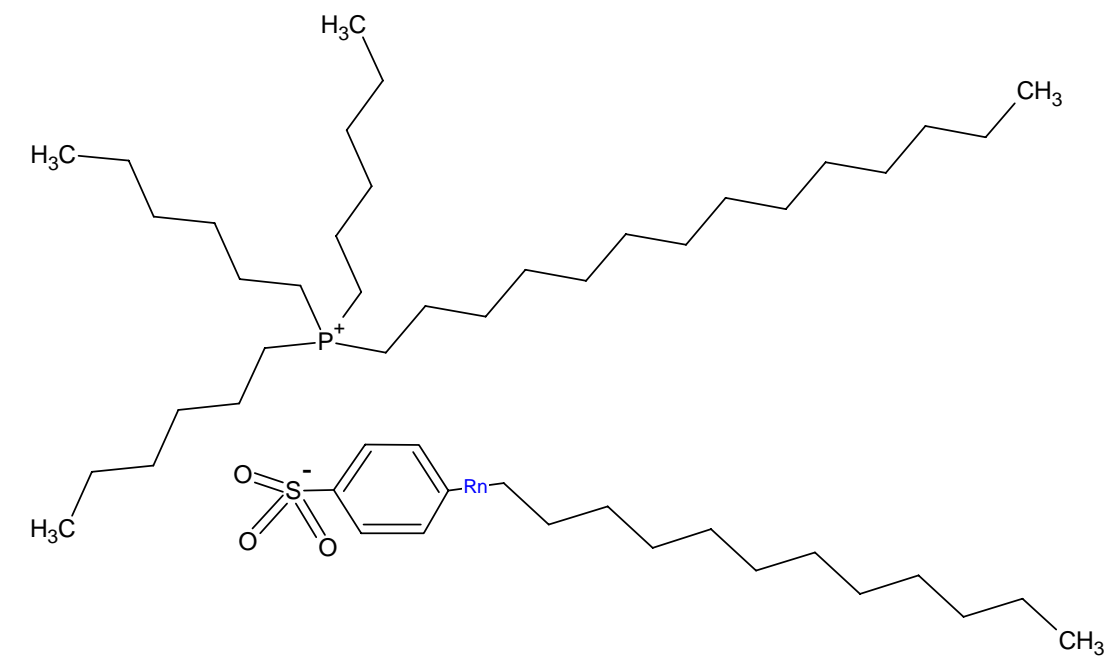

Fig. 2. Trihexyltetradecylphosphonium dodecylbenzenesulfonates. The ' $\mathrm{Rn}$ ' bond indicates different ring bonding sites of the alkane chain.

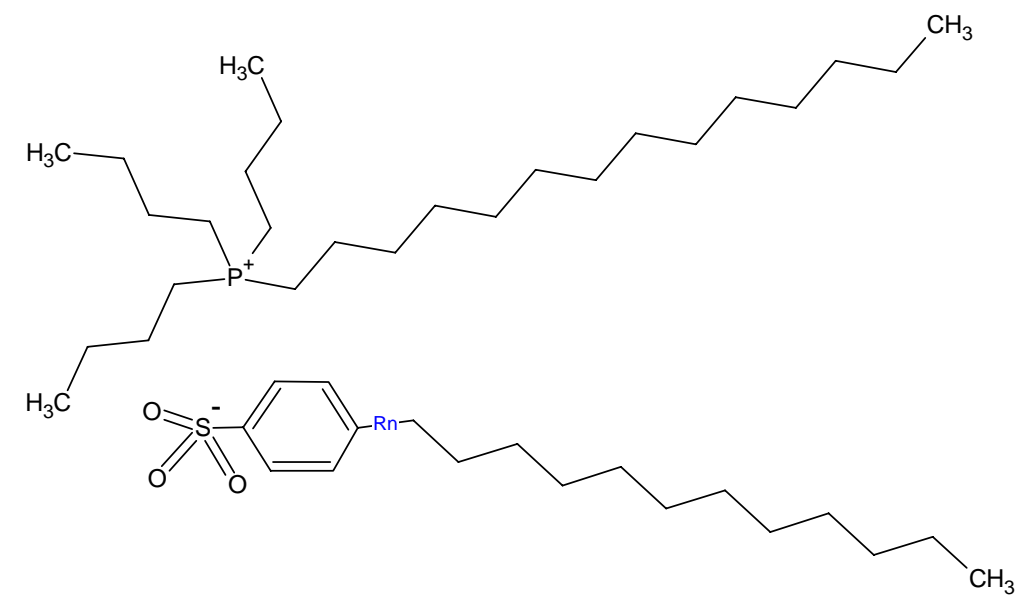

Fig. 3. Tributyltetradecylphosphonium dodecylbenzenesulfonates. The ' $\mathrm{Rn}$ ' bond indicates different ring bonding sites of the alkane chain.

\subsection{PROCEDURES}

The ionic liquids were tested under different conditions of temperature, $\mathrm{pH}$, salinity, and contact time. A typical experiment used a contact ratio of 1:10 (solvent-to-aqueous). The mixture was then shaken hard by hand for $3 \mathrm{~min}$, centrifuged for $15 \mathrm{~min}$ at $1000 \mathrm{rpm}$, and left overnight to help separate the phases (as the aqueous phase was sometimes cloudy) and reach equilibrium. After contact and separation, the $\mathrm{pH}$ of the aqueous phase was measured, followed by filtration through a $0.2-\mu \mathrm{m}$-pore-size filter, and finally injected into a high-performance liquid chromatograph (HPLC). The mobile phase (filtered $5 \mathrm{mM}$ $\left.\mathrm{H}_{2} \mathrm{SO}_{4}\right)$ of the HPLC was pumped at $0.6 \mathrm{~mL} / \mathrm{min}$ through a $300 \times 7.8 \mathrm{~mm}(8-\mu \mathrm{m}$-particle-size $) \mathrm{RHM}$ Monosaccharide column (Phenomenex, Torrance, CA) held at a temperature of $65^{\circ} \mathrm{C}$ to a refractive index detector (Model 2410, Waters Corporation, Miltford, MA) held at a temperature of $40^{\circ} \mathrm{C}$. The sample injection volume was $10 \mu \mathrm{L}$, and the resulting chromatograms were compared with injections of acid standards or controls not in contact with the ionic liquid to compare the amount of organic acid extracted into the ionic liquid. A schematic of the procedure is shown in Fig. 4. 


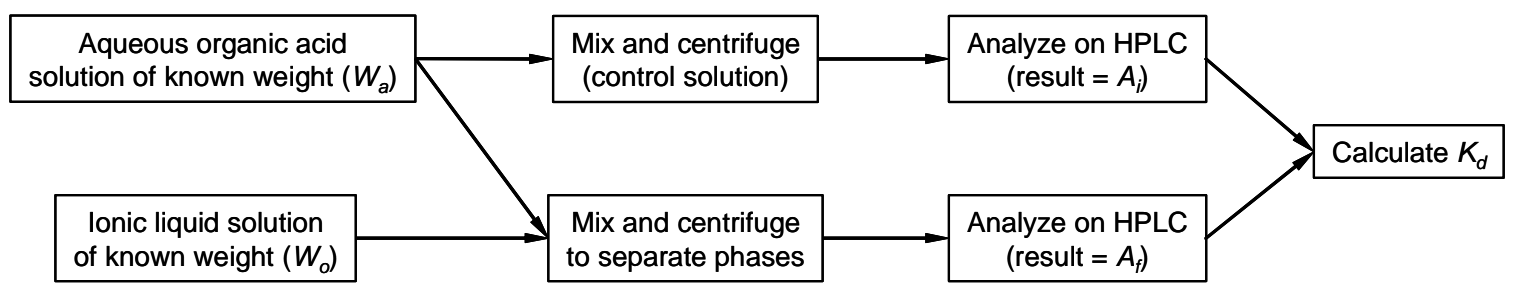

Fig. 4. Schematic of experimental procedure.

The ionic liquids trihexyltetradecylphosphonium methanesulfonate, trihexyltetradecylphosphonium dodecylbenzenesulfonates, and tributyltetradecylphosphonium dodecylbenzenesulfonate (each with 50\% nonanol) were also mixed with trioctylamine (TOA) as a diluent in at $1 \mathrm{~mol} \mathrm{TOA} / \mathrm{kg}$ of ionic liquid/nonanol mixture. Trioctylamine was chosen as the diluent based on results in the literature (11). These three ionic liquids were the only ones able to dissolve trioctylamine after stirring for $24 \mathrm{~h}$.

One of the most important variables measured was the distribution coefficient, $K_{d}$. It was defined as the ratio between the concentrations of the solute (e.g., succinic acid) in the organic phase and in the aqueous phase after contact. As the organic phase concentration could not be measured directly using the HPLC, it was calculated from the aqueous-phase concentration according Eq.(1) and the schematic shown in Fig. 4:

$$
K_{d}=\frac{W_{a}\left(A_{i}-A_{f}\right)}{W_{o} A_{f}},
$$

where

$$
\begin{aligned}
& W_{a}=\text { weight of the aqueous phase, } \\
& W_{o}=\text { weight of the organic (ionic liquid) phase, } \\
& A_{i}=\text { initial concentration of solute in the aqueous phase = concentration of solute in the control } \\
& \text { sample, } \\
& A_{f}=\text { final (equilibrium) concentration of solute in the aqueous phase. }
\end{aligned}
$$

\section{RESULTS}

Scoping tests with butylmethylimidazolium bis(trifluoromethanesulfonyl)imide did not produce very promising results for either acidic, lactic, or succinic acid (data not shown). These results were in agreement with those of Matsumoto et al. (15), who tested some of the same imidazolium-based ionic liquids for extraction of carboxylic acids from fermentation medium and obtained $\mathrm{K}_{\mathrm{d}}$ value of 1 or less. In fact, we speculate that this ionic liquid interfered with the HPLC analysis of succinic acid, often producing unreasonable results. Other research has shown that this ionic liquid has a nonnegligible solubility in water, $8 \mathrm{~g} / \mathrm{L}(18)$. Tests with octylmethylimidazolium bis(trifluoromethanesulfonyl)imide and butylmethylimidazolium hexafluorophosphate also gave disappointing results. This was true when nonanol was added as a diluent as well, often producing calculated values of $K_{d}$ that were less than zero (data not shown). Negative values of $K_{d}$ arise when the measured concentration in the aqueous phase after equilibrium exceeds the concentration in control samples (see Fig. 4). These unreasonable results may be caused by interferences in the analyses of organic acids present at low concentrations $(\sim 1 \mathrm{~g} / \mathrm{L})$ because of increased background levels by ionic liquids with aqueous solubilities of a few weight percent. (19) 
Scoping studies with the ionic liquids purchased from Merck did not produce very promising results ( Fig. 5). These ionic liquids were not able to extract much of the organic acids when contacted with the extractant at approximate ratio of 10 (aqueous solution to organic extractant mixture). This was true for any of the pHs studied: low, medium, and high.

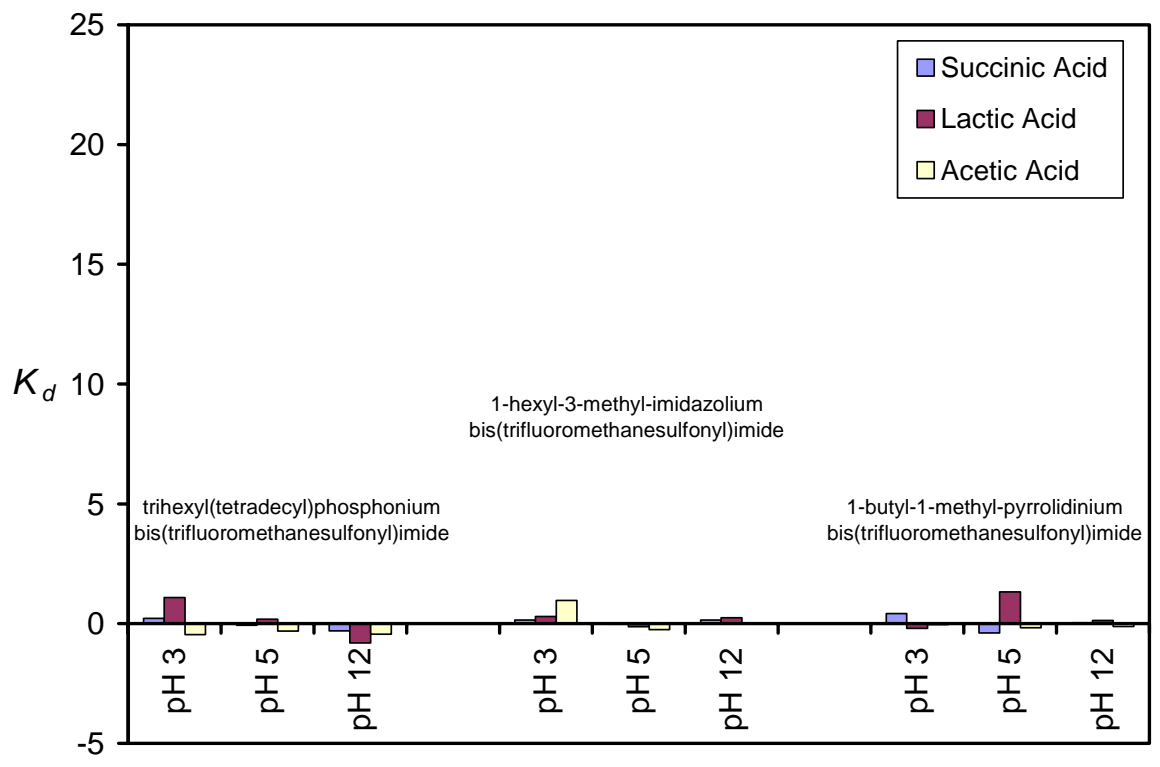

Fig. 5. Results from scoping studies with ionic liquids from Merck. The $x$-axis is labeled with the initial $\mathrm{pH}$ of the aqueous phase. The final $\mathrm{pH}$ did not differ much for the lower pHs. For the high-pH case, the $\mathrm{pH}$ dropped 1-2 units. The initial concentrations of organic acids were $1 \mathrm{~g} / \mathrm{L}$.

Scoping studies with the ionic liquids with sulphonate(s)-based anions showed some promise. The greatest extraction efficiency was noted for succinic acid. Each of the organic acids was present at $\sim 1 \mathrm{~g} / \mathrm{L}$ and contacted with the extractant at approximate ratio of 10 (aqueous solution to organic extractant mixture [ Fig. 6]). The best-performing ionic liquid was trihexyltetradecylphosphonium methanesulfonate/nonanol, which worked well for all the organic acids, especially when the initial aqueous $\mathrm{pH}$ was high.

The efficiency of extraction of succinic acid was studied further at additional $\mathrm{pH}$ ranges. The TOA/ionic liquid/nonanol mixtures were contacted with approximately $1 \mathrm{~g} / \mathrm{L}$ succinic acid solution at $\mathrm{pH} 3, \mathrm{pH} 5$, and $\mathrm{pH}$ 6.5. This range of $\mathrm{pHs}$ bracketed the $p K_{a}$ values of succinic acid of 4.2 and 5.6 (20). The contacts consisted of $0.5 \mathrm{~mL}$ of solvent and $5 \mathrm{~mL}$ of succinic acid stock solution. The control was succinic acid stock solution not in contact with the solvent mixture. The contacts were then left in the refrigerator overnight or allowed to remain at room temperature. The results for room temperature conditions are shown in Fig. 7. As is noted, the use of trihexyltetradecylphosphonium methanesulfonate as the ionic liquid constituted a superior extraction solvent. In Fig. 8, the results for extractions systems refrigerated overnight are shown. As is noted, aqueous-organic phase equilibrium for succinic acid established at refrigeration temperature shows lower $K_{d}$ values. All the experiments indicated that a $\mathrm{pH}$ below the lowest $\mathrm{pKa}$ (4.2) did not give the best results. These results are different from some of the results obtained by Huddleston et al., who found the noncharged form of organic acids are more prone to extraction by butylmethylimidazolium hexafluorophosphate (21). 


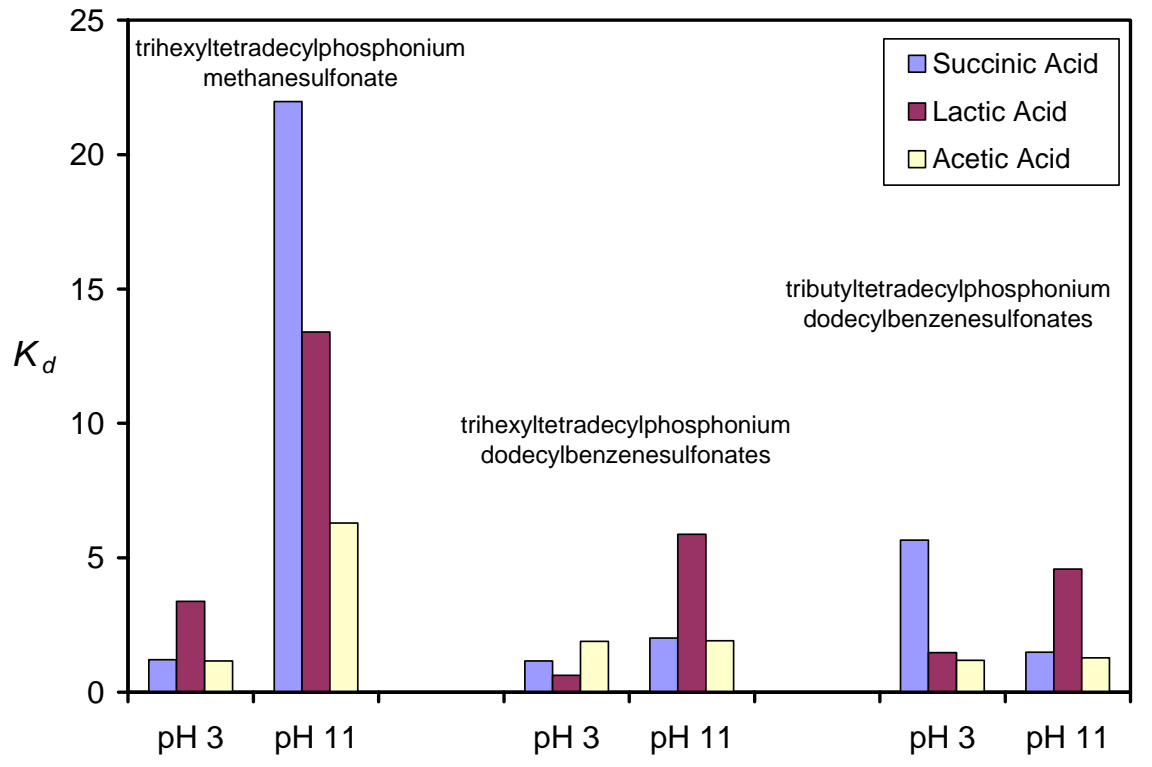

Fig. 6. Scoping studies with ionic liquid containing sulfonate(s) anions. All these ionic liquids were diluted with about $50 \mathrm{vol} \%$ nonanol. The $x$-axis is labeled with the initial $\mathrm{pH}$ of the aqueous phase. The final $\mathrm{pH}$ was $2.5-4.6$ for the low-pH and 6.6-9.5 for the high-pH case.

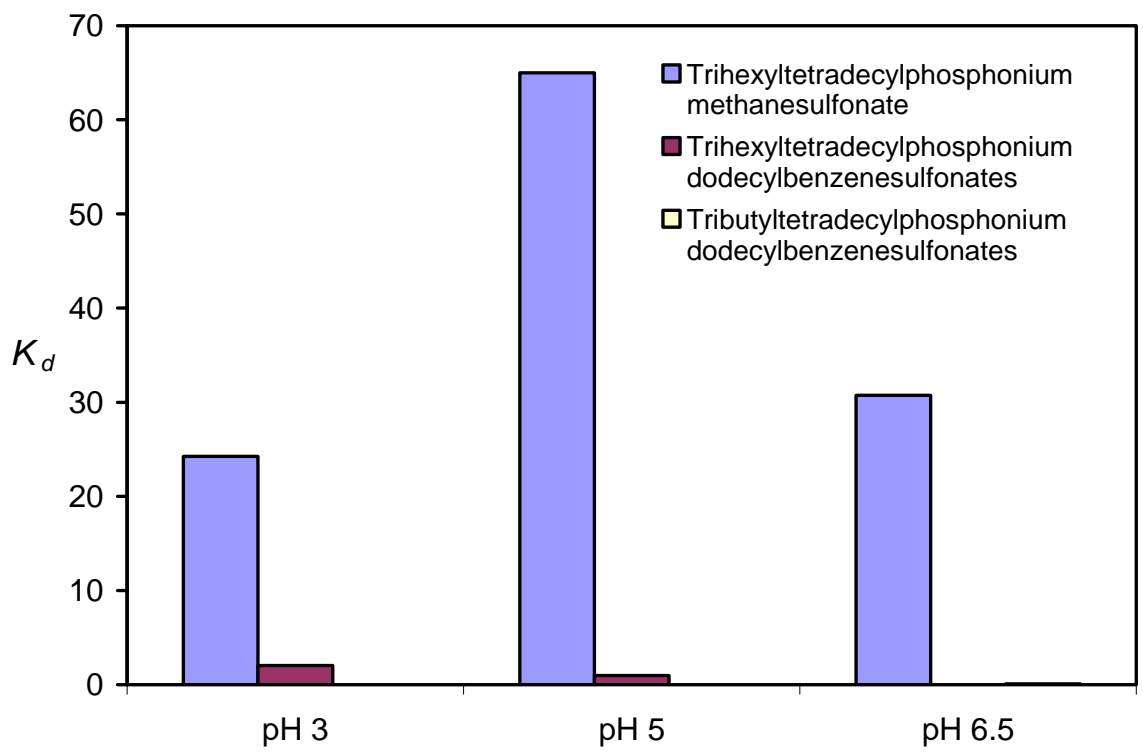

Fig. 7. Succinic acid distribution coefficient as a function of $\mathbf{p H}$ at room temperature for different TOA/ionic liquid/nonanol mixtures. 


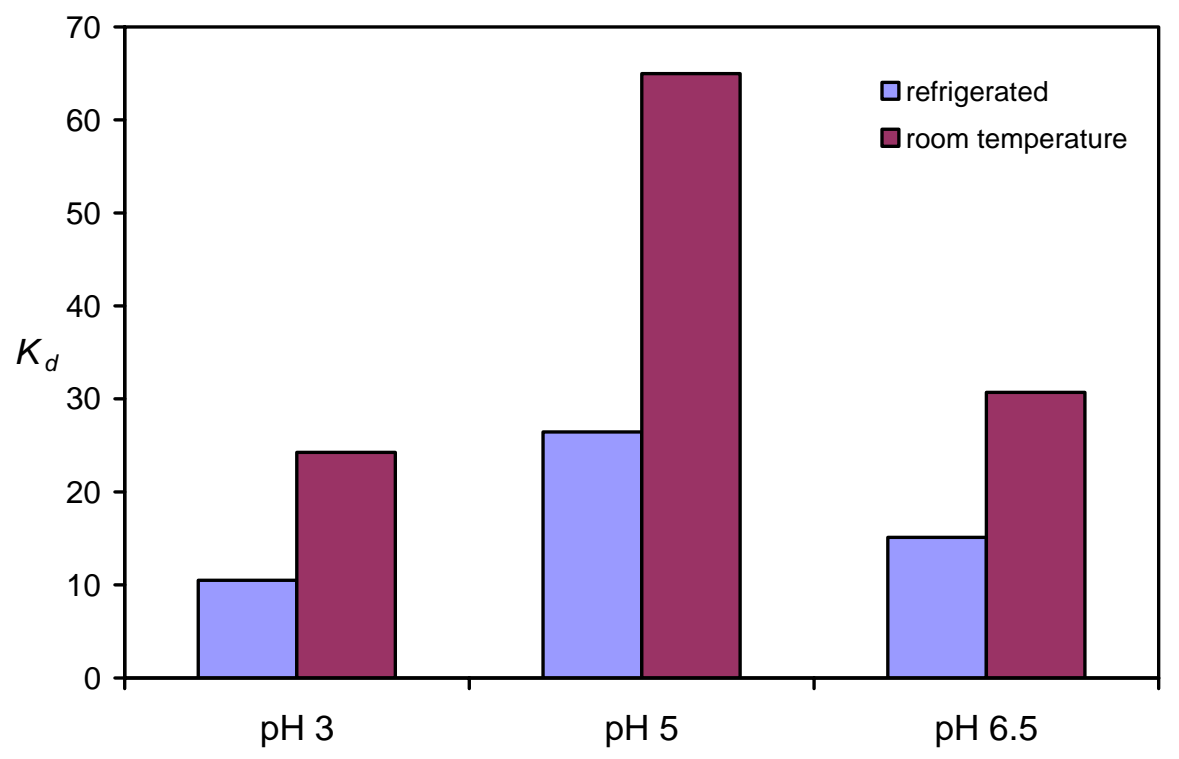

\section{Fig. 8. Succinic acid distribution coefficient for different temperatures with TOA/trihexyltetradecylphosphonium methanesulfonate/nonanol.}

To investigate if the extraction system consisting of ionic liquids with sulfonate(s) anions (each with 50 vol \% nonanol and TOA) performed better than other traditional solvent mixtures, contacts were also made to duplicate the experiment of Hong (11) for comparison. These contacts consisted of $3 \mathrm{~mL}$ of 1 mol TOA/kg of octanol mixture (made by stirring two hours) and $3 \mathrm{~mL}$ of stock solution with $1 \mathrm{~g} / \mathrm{L}$ succinic acid. Control experiment contacts were also made with $0.5 \mathrm{~mL}$ of TOA$/ \mathrm{kg}$ octanol mixture and deionized water. In parallel experiments, the three ionic liquids with sulphonate(s) anions were used. As noted in Fig. 9, the TOA/octanol performed as poorly as the some of the ionic liquids. However, the capacity of the TOA/octanol for succinic acid may be greater-Hong reported that a distribution coefficient of approximately 11 was obtained when an aqueous solution with $33 \mathrm{~g} / \mathrm{L}$ of succinic acid was contacted with an equal volume of octanol containing $1 \mathrm{~mol} \mathrm{TOA} / \mathrm{kg}$. In our project, the opposite correlation was observed - higher $K_{d}$ values were noted when the extraction of succinic acid from water was carried out at very low concentration (e.g., $1 \mathrm{~g} / \mathrm{L}$ ) than at higher values.

The effect of succinic acid concentration on the distribution coefficient is shown in Fig. 10. As is noted, there is a strong dependence between $K_{d}$ and the succinic acid concentration. At low concentration of succinic acid in the aqueous phase, the $K_{d}$ is large, which by definition means a preference of the succinic acid to distribute into the ionic liquid phase. 


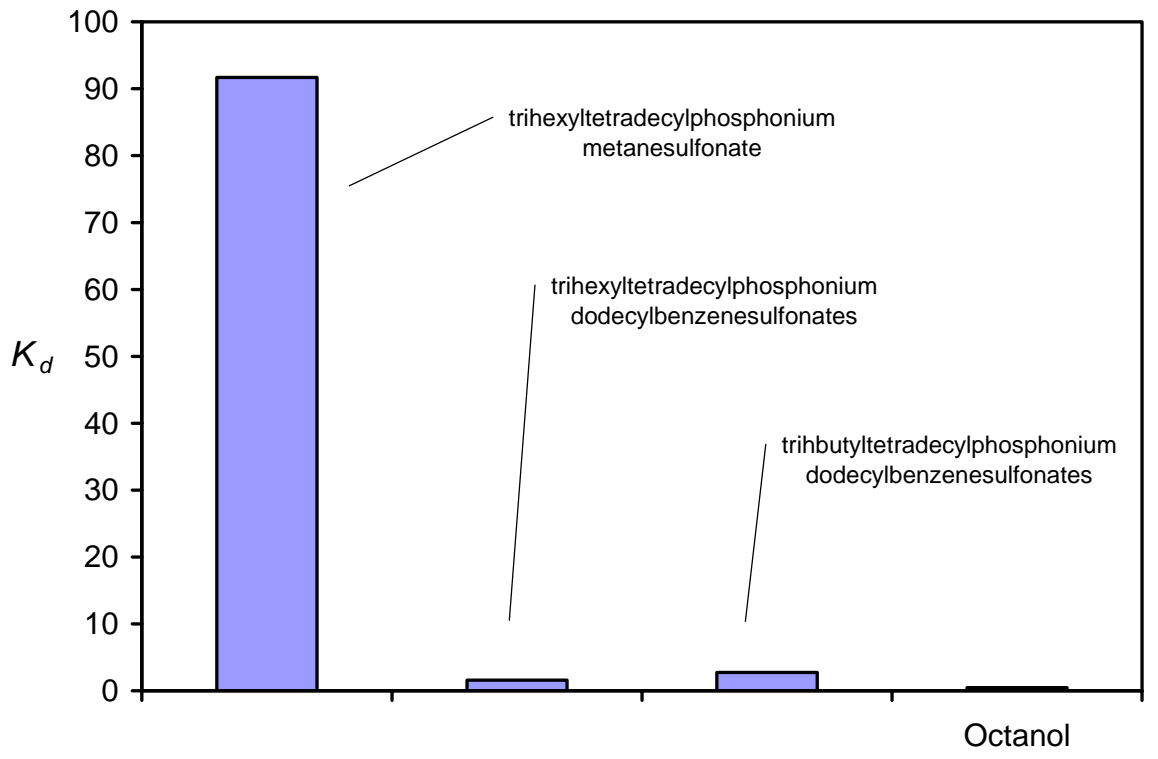

Fig. 9. Results from comparison study with extraction solvent suggested by

Hong. Each of the ionic liquids was diluted with $50 \mathrm{vol} \%$ nonanol, and all extraction solvent mixtures contained $1 \mathrm{~mol} \mathrm{TOA} / \mathrm{kg}$ of solvent. The final $\mathrm{pH}$ was 4.7-5.3.

\subsection{EXTRACTION OF SUCCINIC ACID FROM FERMENTATION MEDIUM}

The $1 \mathrm{~mol} \mathrm{TOA} / \mathrm{kg}$ of $50 \mathrm{vol} \%$ trihexyltetradecylphosphonium methanesulfonate/nonanol solvent mixture was tested with the succinic acid fermentation medium to determine if the medium would affect the extraction coefficient of the solvent. The medium used is shown in Table 1 . The $\mathrm{pH}$ of the medium was adjusted to 6.5 with concentrated phosphoric acid. The medium was then contacted with extraction solvent in a 1:10 ratio. The aqueous phase was analyzed in the HPLC along with medium without succinic acid (to determine if the medium had any peaks inhibiting the peak of succinic acid) and medium with succinic acid (which was a control).

Extraction of succinic acid from this medium did not appear much different than extraction of the same acid from distilled water. The value of $K_{d}$ was 1.5 when the fermentation medium was contacted with the mixture of trihexyltetradecylphosphonium methanesulfonate/nonanol/TOA. In the case of extraction from distilled water (under the same conditions), the $K_{d}$ was 1.0. Although the $K_{d}$ for the fermentation medium was $60 \%$ higher, these low $K_{d}$ 's were prone to experimental error. In practice, it is appropriate to say that the $K_{d}$ 's were essentially the same. 


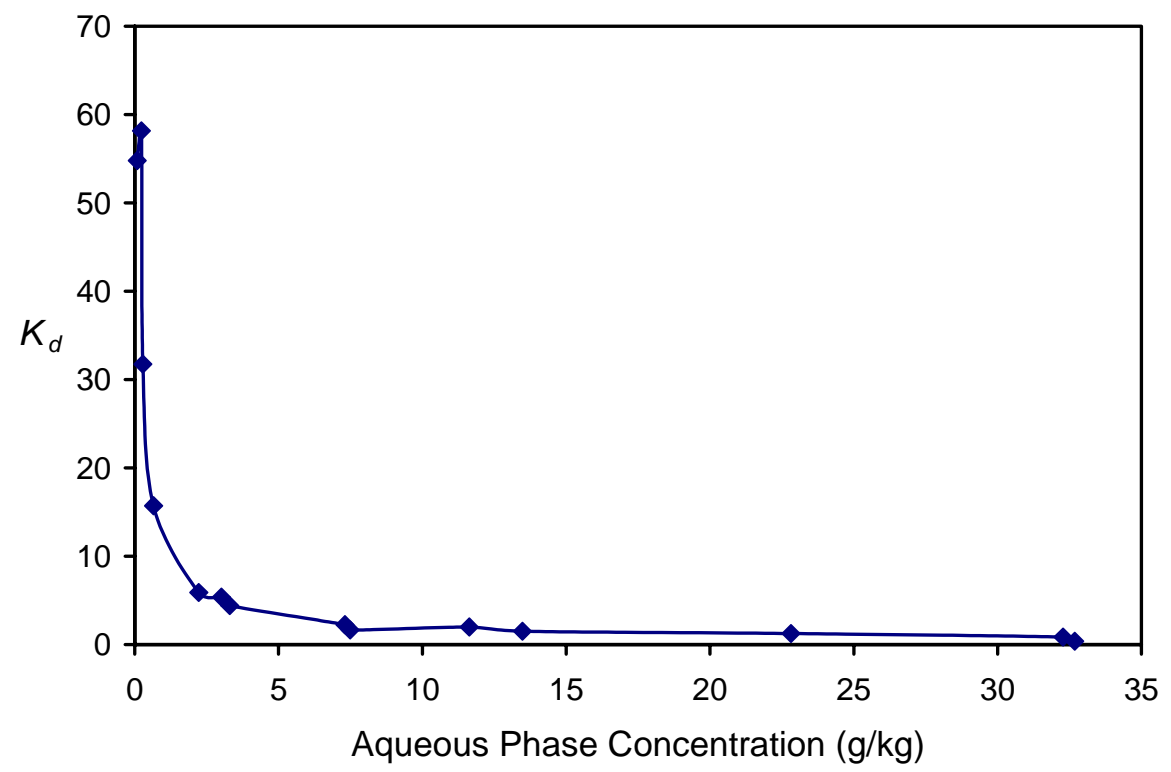

Fig. 10. Distribution coefficient as a function of succinic acid concentration. $\mathrm{Kd}$ was measured between a $13 \pm 3$ mass ratio of succinic acid aqueous solution and a mixture of $50 \mathrm{vol} \%$ trihexylxtetradecylphosphonium methanesulfonate-50\% $1 \mathrm{~mol}$ $\mathrm{TOA} / \mathrm{kg}$ octanol.

Table 1. Fermentation medium for production of succinic acid

\begin{tabular}{cc}
\hline Chemical & Concentration $(\mathrm{g} / \mathrm{L})$ \\
\hline Yeast extract & 2 \\
$\mathrm{~K}_{2} \mathrm{HPO}_{4}$ & 1.4 \\
$\mathrm{KH}_{2} \mathrm{PO}_{4}$ & 0.6 \\
$\left(\mathrm{NH}_{4}\right)_{2} \mathrm{SO}_{4}$ & 2 \\
$\mathrm{MgSO}_{4}$ & 0.2 \\
Tryptone peptone & 5 \\
Succinic acid & 33 \\
Glucose 50 wt \% & 2 \\
\hline
\end{tabular}

\subsection{ESTIMATION OF CONTINUOUS LIQUID-LIQUID EXTRACTION REQUIREMENTS}

In order to predict the number of unit operations needed to extract succinic acid from an aqueous phase with an ionic liquid solvent, Fig. 11 was generated. Data from several experiments were plotted, and an approximate equilibrium curve was drawn through the points. The working line, corresponding to an assumed ratio of $0.7 \mathrm{~kg} / \mathrm{kg}$ aqueous-to-ionic liquid flows, was drawn for ideal extraction stages (22). As is noted in Fig. 11, two ideal stages are needed to reduce the succinic aqueous phase from $33 \mathrm{~g} / \mathrm{kg}$ to 1 $\mathrm{g} / \mathrm{kg}$. The equivalent flow chart showing the unit operation with two extraction stages is shown in Fig. 12. 


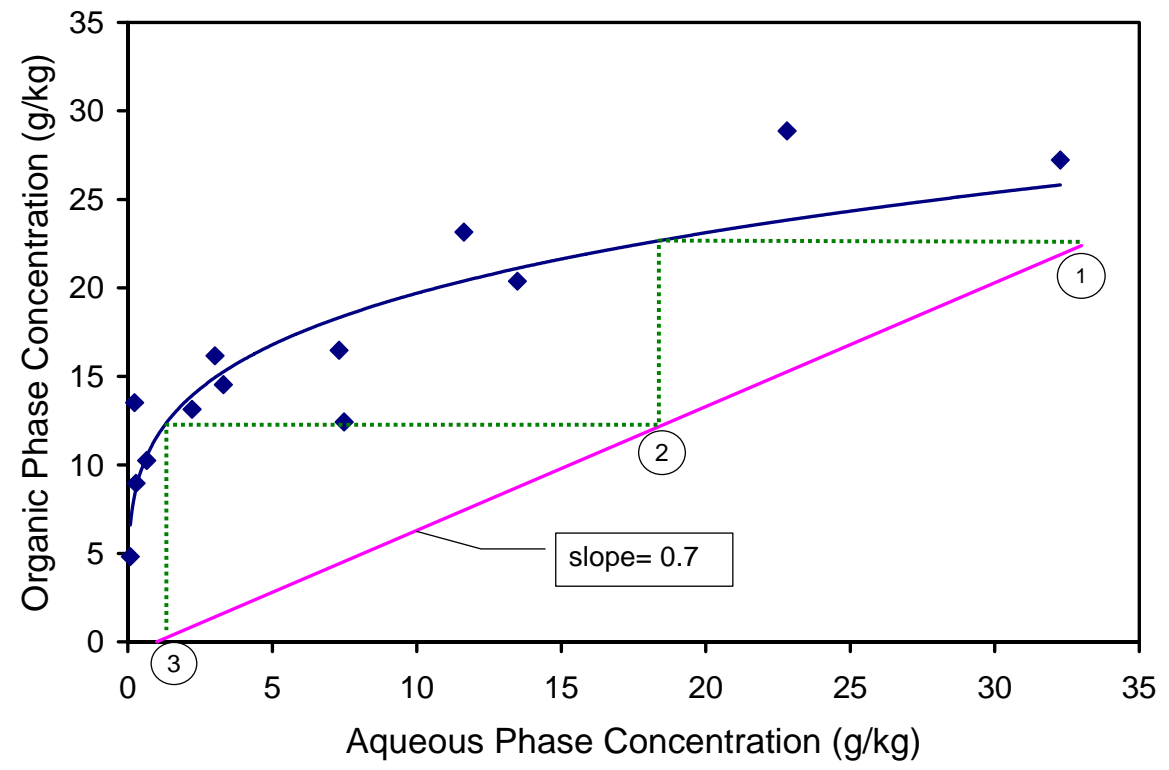

Fig. 11. Equilibrium diagram and working graph for determining theoretical extraction stages.

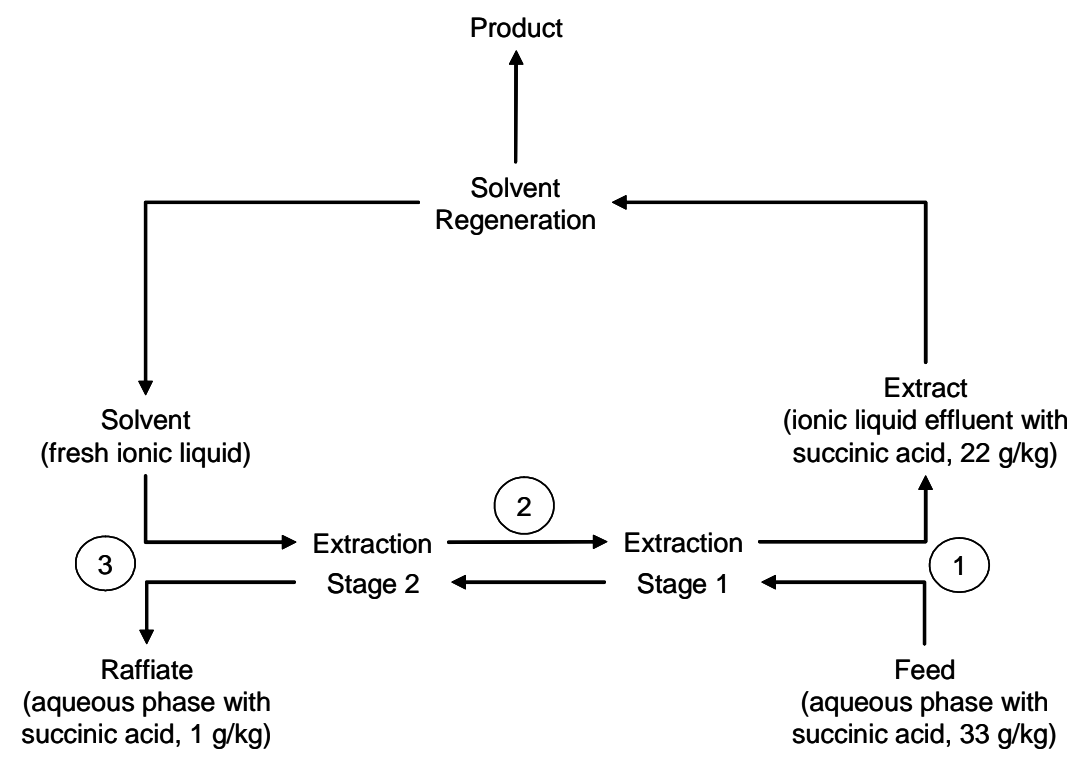

Fig. 12. Schematic of extraction stages for succinic acid extraction from aqueous to ionic liquids. 


\section{CONCLUSIONS}

Several ionic liquids have been investigated for the extraction of organic acids from fermentation broth. Most of the tests with ionic liquids failed to give promising results, and further experiments were not pursued. The extraction efficiencies were (not surprisingly) strongly dependent on the $\mathrm{pH}$ of the aqueous phase. Distribution coefficients were very good (approximately 60) at low succinic acid concentrations for one of the ionic liquids (trihexyltetradecylphosphonium methanesulfonate) at neutral $\mathrm{pH}$. However, this ionic liquid had to be diluted with nonanol due to its high viscosity in order to be useful. A diluent (trioctylamine) was also added to this mixture to improve performance. The results suggest that an extraction system based on ionic liquids may be feasible for succinic acid recovery from fermentation broth and that two ideal extraction stages are needed to reduce the concentration from $33 \mathrm{~g} / \mathrm{L}$ to $1 \mathrm{~g} / \mathrm{L}$ of succinic acid.

It should be noted that this report contains preliminary results. Further studies are needed in the following areas:

1. Studies with controlled $\mathrm{pH}$ : The $\mathrm{pH}$ was not "controlled" in the present studies. Effort was made in many cases to adjust $\mathrm{pH}$ during contact if it had drifted too far from the desired value.

2. Measurement of ionic liquid losses: No effort was made in the present studies to estimate the loss of ionic liquid in the extraction sequence.

3. Recovery of organic acid from the ionic liquid: No effort was made to recover the organic acid (e.g., succinic acid) from ionic liquid after extraction. Some of the results suggest that both temperature swing and $\mathrm{pH}$ swing may be useful methods.

4. Toxicity studies of ionic liquid: The present study was performed based on the idea that the acids would be extracted after fermentation. If extraction is simultaneous to fermentation, the toxicity of the ionic liquids on the microbial culture must be determined.

\section{REFERENCES}

1. K. N. Marsh, A. Deev, A. C.-T. Wu, E. Tran, and A. Klamt, "Room Temperature Ionic Liquids as Replacements for Conventional Solvents-A Review," Korean J. Chem. Eng. 19(3), 357-362 (2002).

2. K. N. Marsh, J. A. Boxall, and R. Lichtenthaler, "Room Temperature Ionic Liquids and Their Mixtures-A Review," Fluid Phase Equilib. 219, 93-98 (2004).

3. A. M. Baniel and A. M. Eyal, “Citric Acid Extraction,” U.S. Patent 5,426,220 (June 20, 1995).

4. A. M. Baniel et al., "Lactic Acid Production, Separation and/or Recovery Process," U.S. Patent 5,510,526 (April 23, 1996).

5. A. M. Baniel et al., "Lactic Acid Production, Separation and/or Recovery Process," U.S. Patent 5,780,678 (July 14, 1998).

6. A. M. Baniel, "Recovery of Carboxylic Acid from Organic Solution that Contains an Amine and an Extraction Enhancer," U.S. Patent 5,780,276 (July 14, 1998).

7. A. M. Baniel, "Recovery of Carboxylic Acid from Organic Solution that Contains an Amine and an Extraction Enhancer," U.S. Patent 5,773,653 (June 30, 1998).

8. J. G. Zeikus, M. K. Jain, and P. Elankovan, "Biotechnology of Succinic Acid Production and Markets for Derived Industrial Products," Appl. Microbiol. Biotechnol. 51, 545-552 (1999). 
9. J. J. Malinowski, “Two-Phase Partitioning Bioreactors in Fermentation Technology," Biotechnol. Adv. 19, 525-538 (2001).

10. Y. Wang and L. E. K. Achenie, "Computer Aided Solvent Design for Extractive Fermentation," Fluid Phase Equilib. 201(1), 1-18 (2002).

11. Y. K. Hong, W. H. Hong, and H. N. Chang, "Selective Extraction of Succinic Acid from Binary Mixture of Succinic Acid and Acetic Acid," Biotechnol. Lett. 22, 871-874 (2000).

12. S. G. Cull, J. D. Holbrey, V. Vargas-Mora, K. R. Seddon, and G. J. Lye, "Room-Temperature Ionic Liquids as Replacements for Organic Solvents in Multiphase Bioprocess Operations," Biotechnol. Bioeng. 69(2), 227-233 (2000).

13. S. V. Smirnova, I. I. Torocheshnikova, A. A. Formanovsky, and I. V. Pletnev, "Solvent Extraction of Amino Acid into a Room Temperature Ionic Liquid with Dicyclohexano-18-crown-6," Anal. Bioanal. Chem. 378(5), 1369-1375 (2004).

14. A. G. Fadeev and M. M. Meagher, "Opportunities for Ionic Liquids in Recovery of Biofuels," Chem. Comm. 2001(3), 295-296 (2001).

15. M. Matsumoto, K. Mochiduki, K. Fukunishi, and K. Kondo, "Extraction of Organic Acids Using Imidazolium-Based Ionic Liquids and Their Toxicity to Lactobacillus rhamnosus," Sep. Purif. Technol. 40, 97-101 (2004).

16. S. Snyder, J. Hestekin, and B. Davison, Direct Capture of Products from Biotransformations, ANL/ES/RP-107070, Argonne National Laboratory, Argonne, Ill., March 2002.

17. A. Berthod and S. Carda-Broch, "A New Class of Solvents for CCC: The Room Temperature Ionic Liquids,” J. Liquid Chromatogr. Relat. Technol. 26(9), 1493-1508 (2003).

18. H. Luo, S. Dai, and P. V. Bonnesau, "Solvent Extraction of $\mathrm{Sr}^{2+}$ and $\mathrm{Cs}^{+}$Based on RoomTemperature Ionic Liquids Containing Monoaza-Substituted Crown Ethers," Anal. Chem. 76, 2773 2779 (2004).

19. J. L Anthony, E. J. Magninn, and J. F. Brennecke, "Solution Thermodynamics of Imidazolium-Based Ionic Liquids and Water," J. Phys. Chem. B 105, 10942-10949 (2001).

20. Lange's Handbook of Chemistry, 13th ed., McGraw-Hill, New York, 1985, pp. 5-56.

21. J. G. Huddleston, H. D. Willauer, R. P. Swatloski, A. E. Visser, and R. D. Rogers, "Room Temperature Ionic Liquids as Novel Media for 'Clean' Liquid-Liquid Extraction," Chem. Commun. 1998(16), 1765-1766.

22. Perry's Handbook of Chemical Engineering, 7th ed., McGraw-Hill, New York, 1997, pp. 15-17, 1518. 
ORNL/TM-2004/192

\section{INTERNAL DISTRIBUTION}

1. J. F. Birdwell, Jr.

2. M. A. Brown

3. R. M. Counce

4. S. Dai

5. B. H. Davison

6. D. W. DePaoli
7. M. A. Karnitz

8. H. Luo

9. J. McFarlane

10. S. M. Robinson

11. C. Tsouris

12. ORNL OTIC, OSTI, CRL

\section{EXTERNAL DISTRIBUTION}

13. R. E. Baltus, Department of Chemical Engineering, Clarkson University, Potsdam, NY 13699

14. K. T. Klasson, Southern Regional Research Center, USDA-ARS, 1100 Robert E. Lee Blvd., New Orleans, LA 70124

15. S. A. Morton, Department of Chemical Engineering, Lafayette College, Easton, PA, 18042

16. C. Oliphant, Energy Division, Department of Economic and Community Development, Department of Tennessee, 312 Eight Ave., North, Nashville, TN 37243

17. R. Ren, Department of Chemistry, Wesleyan University, Middleton, CT 06459

18. W. B. Ridenour, Department of Biochemistry, M407 Walters Life Sciences Building, University of Tennessee, Knoxville, TN 37996-08400 